\title{
Dialogue with the reader in the journalism of F. M. Dostoevsky (on the example of the article "The Case of the Dzhunkovskys with their own children")
}

\author{
S. A. Besogonova ${ }^{1}$, E. A. Fedorova ${ }^{1}$
}

1P. G. Demidov Yaroslavl State University, 14 Sovetskaya str., Yaroslavl 150003, Russian Federation

DOI: $10.18255 / 2412-6519-2021-3-326-333$

Research Article

Full text in Russian

The purpose of this article is analyze the methods of organizing the author's dialogue with his reader. the journalistic texts of F. M. Dostoevsky, taken from the "Diary of a Writer" for 1876 and 1877 are the material for this article.

The article discusses the ideas of the dialogue of M. M. Bakhtin, Yu. M. Lotman and others and explains how the reader enters into communication with the author. In addition, the methods of organizing a dialogue with the reader in the journalism of F. M. Dostoevsky on the topic of child suffering are analyzed: the articles «Berries» (in the case of S. L. Kroneberg) and «A simple but complicated case» (in the case of E. K. Kornilova) are reviewed in detail, the article «The case of the Dzhunkovskys with their own children» is analyzed in detail. On the basis of the communicative analysis, the speech tactics used during Dostoevsky's dialogue with his reader are distinguished: the tactics of opposition, the tactics of concession, the tactics of generalization, and others, as well as different types of dialogical relations (agreement and disagreement), different vectors of the author's attention (the court, the Dzhunkovsky family, the reader) are described and features of autocommunication. In addition, parallels are drawn with Dostoevsky's literary text-the novel "The Brothers Karamazov": reflections on the episode about a child's tear are given.

Keywords: F. M. Dostoevsky; The Writer's Diary; speech tactics; dialogue; autocommunication; humanism

INFORMATION ABOUT THE AUTHORS

$$
\begin{array}{r|l}
\begin{array}{r}
\text { Besogonova, Svetlana A. } \\
\text { (correspondence author) }
\end{array} & \begin{array}{l}
\text { E-mail: bess.sweta@yandex.ru } \\
\text { Student }
\end{array} \\
\text { Fedorova, Elena A. } & \begin{array}{l}
\text { Email: sole11@yandex.ru } \\
\text { Doc. Sc. (Philology), Associate Professor }
\end{array}
\end{array}
$$

Funding: RFBR, project 18-012-90036

For citation: Besogonova S. A., Fedorova E. A. Dialogue with the reader in the journalism of F. M. Dostoevsky (on the example of the article «The Case of the Dzhunkovskys with their own children») // Social'nye i gumanitarnye znanija. 2021. Vol. 7, No 3. P. 326-333. (in Russ.) 


\title{
Диалог с читателем в публицистике Ф. М. Достоевского (на примере статьи «Дело Джунковских с родными детьми»)
}

\author{
С. А. Бесогонова ${ }^{1}$, Е. А. Федорова ${ }^{1}$
}

1Ярославский государственный университет им. П. Г. Демидова, ул. Советская, 14, Ярославль, 150003, Российская Федерация

DOI: $10.18255 / 2412-6519-2021-3-326-333$

УДК 821.161 .1

Научная статья Полный текст на русском языке

Целью настоящей статьи является анализ приемов организации диалога автора со своим читателем. Материалом для статьи послужили публицистические тексты Ф. М. Достоевского, взятые из «Дневника писателя» за 1876 и 1877 гг.

В статье рассматриваются идеи диалога М. М. Бахтина, Ю. М. Лотмана и других исследователей, объясняется, каким образом читатель вступает в коммуникацию с автором. Кроме того, анализируются приемы организации диалога с читателем в публицистике Ф. М. Достоевского на тему страдания ребенка: обзорно рассматриваются статьи «Ягодки» (по делу С. Л. Кронеберга) и «Простое, но мудреное дело» (по делу Е. К. Корниловой), подробно проанализирована статья «Дело Джунковских с родными детьми». На основе коммуникативного анализа выделяются речевые тактики, используемые в ходе диалога Достоевского со своим читателем: тактика противопоставления, тактика уступки, тактика обобщения и другие, а также описываются разные виды диалогических отношений (согласие и несогласие), разные векторы авторского внимания (суд, семья Джунковских, читатель) и особенности автокоммуникации. Кроме того, проводятся параллели с художественным текстом Достоевского - романом «Братья Карамазовы»: приведены размышления над речью Ивана Карамазова о слезинке ребенка.

Ключевые слова: Ф. М. Достоевский; Дневник писателя; речевые тактики; диалог; автокоммуникация; гуманизм

\section{ИНФОРМАЦИЯ ОБ АВТОРАХ}

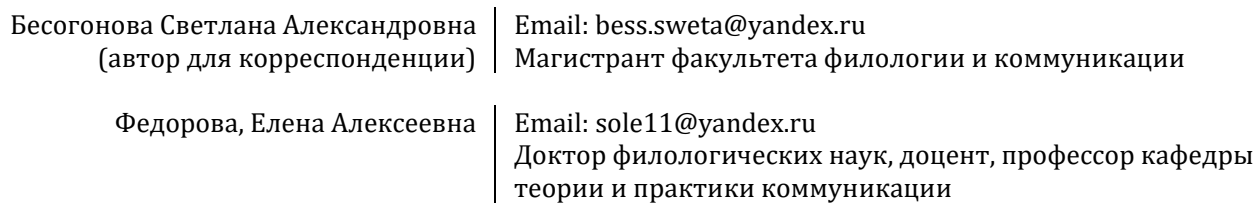

Финансирование: РФФИ, проект № 18-012-90036 «Достоевский в средней и высшей школе: проблемы и новые подходы».

Для цитирования: Бесогонова С. А., Федорова Е. А. Диалог с читателем в публицистике Ф. М. Достоевского (на примере статьи «Дело Джунковских с родными детьми») // Социальные и гуманитарные знания. 2021. Том 7, № 3. С. 326-333.

(C) Бесогонова С. А., Федорова Е. А., 2021

Статья открытого доступа под лицензией СС BY (https://creativecommons.org/licenses/by/4.0/) 
Обычно понятие «диалог» используется в двух областях коммуникации - житейски-бытовой и научно-философской. В первом случае диалог означает собеседование двух лиц. Во втором - информационное взаимодействие людей как субъектов, независимо от использованных речевых или иных семиотических средств, его целью является повышение степени их духовной общности или достижение этой общности [1, с. 150].

Выявляя сущностную основу диалога, В. А. Подорога рассматривает специфику структуры коммуникации: «Диалог - это живая форма общения, по крайней мере, двух субъектов, которые разными способами включаются в единое поле высказывания. Речь, обращенная к другому, уже несет в себе фрагменты речи того, к кому она обращена, диалог - это пред-понимающая структура смысла» [2, с. 278]. Э. В. Сайко отмечает, что «диалог, будучи формой общения, имеет свою самостоятельную природу, определяющую соответствующую специфическую роль его в культурно-историческом процессе: диалог- общение не равен общению» [3].

Идея диалога пронизывает всю онтологию М. М. Бахтина. В книге «Проблемы поэтики Достоевского» содержится характерное высказывание: «Быть - значит общаться диалогически» [4, с. 338]. Основные категории, описывающие конкретный поступок, - это «я для себя», «другой для меня» и «я для другого». Философия диалога Бахтина оказывается логически полной и завершенной. В ранних произведениях «К философии поступка» и «Автор и герой в эстетической деятельности» (начало 20-х годов XX века) - Бахтин представляет феноменологию «я». В книге о Достоевском (конец 20-х годов XX века) предлагается описание диалога «я» и «ты». В поздних работах - в частности, в книге «Творчество Франсуа Рабле и народная культура средневековья и Ренессанса» (30-40-е годы XX века) - показана третья ступень диалога: ситуация подчинения «я» другому, выражаясь словами Бахтина, «одержания» «я» другим [5, с. 84-85].

На наш взгляд, наиболее «диалогичным» из всего текстового пространства является публицистический текст, поскольку он нацелен на донесение до читателя общезначимой информации и одновременное воздействие на него. Публицистический текст не просто информирует читателя, а формирует в нем достойного собеседника, со-мыслителя или оппонента.

Для создания благоприятной, плодотворной диалоговой атмосферы в тексте должен содержаться богатый диалоговый ресурс - то самое ценное ядро публицистического текста, складывающееся из его содержания, достоверности, эмоциональности, дискуссионности, актуальности, значимости для большинства [6].

Важно осознавать, что в процессе восприятия читатель становится субъектом единого творчески-рецептивного процесса. Он не просто воспринимает текст как готовую данность, а отвечает на художественную мысль писателя аналогичными движениями своей художественной мысли, то есть вступает с ним в диалог.

Текст читателя рождается из встречи сложного текстового потенциала автора и жизненного, эстетического опыта читателя. Это сотворчество реализуется на трех уровнях: внимания, соучастия, открытия. На уровне внимания читатель вступает в коммуникацию с автором, следуя его художественной логике, созерцая мир, созданный его творческим воображением, внимая его мыслям и чувствам, постигая его авторскую установку. Очевидно, что можно говорить об установке каждого писателя на определенный тип читательского восприятия, вниманием которого он овладевает. Установка задается автором при помощи «системы раздражителей, сознательно и преднамеренно организованных с таким расчетом, чтобы вызвать эстетическую 
реакцию». Только в этом случае текст «впишется» в контекст жизни читателя и прежде всего настоящего бытия, по отношению к которому он как бы станет событием. Но чтобы коммуникация читателя с автором осуществилась, необходимо, чтобы реципиент уловил сюжетно-композиционный, словесно-образный и словесноинтонационный строй текста, то есть то, что вслед за Л. С. Выготским в психологии искусства называют эмоциями формы и эмоциями содержания.

Нам мыслится интересным публицистический текст, который выстраивается наравне с текстом художественным. К примеру, «Дневник писателя» Ф. М. Достоевского.

«Дневник писателя» является публицистическим и одновременно художественным произведением. Замысел нового издания Достоевский вынашивает в конце 60-хгг., вскоре после того, как прекратили свое существование журналы «Время» и «Эпоха». Живя за границей в 1867-1871 гг., Ф. М. Достоевский мечтает возвратиться к публицистической деятельности, о чем свидетельствуют его письма [7, с. 145]. Вот что он пишет С. А. Ивановой, своей племяннице, переводчице, 29 сентября 1867 г.: «Хочу издавать, возвратясь, нечто вроде газеты. Я даже помнится, Вам говорил это вскользь, но здесь теперь совершенно выяснилось и форма и цель... А для этого надо быть дома и видеть и слышать все своими глазами» [8, т. 28, с. 224]. «Дневник писателя», таким образом, несет в себе публицистический дискурс.

Однако нельзя отрицать и того, что в «Дневнике писателя» Достоевский отражал своё видение мира, свои размышления о глобальных проблемах. 0 создании практически всех своих произведений Достоевский пишет именно в «Дневнике писателя», что позволяет исследователям более полно понять автора.

Интересно, что, к примеру, М. М. Бахтин предельно критичен к публицистике Достоевского. Он называет Достоевского «рядовым публицистом своего времени», утверждает, что письмо к реальному адресату было наиболее чуждым ему («ненавистным») словесным жанром [4, с. 325]. Эта асимметрия в оценках романа и публицистики, вероятно, наложила тень на литературную репутацию «Дневника писателя» на протяжении длительного периода (30-80-е гг. XX в.).

Каким же образом выстраивается диалог автора и читателя в публицистике Достоевского?

По мнению Ф.А. Ермошина, в «Дневнике писателя» Достоевский предоставляет своего рода «трибуну» «...не столько потенциальным “друзьям”, сколько, в первую очередь, предполагаемым “врагам”. Истина, по мысли Достоевского, рождалась не только в диалоге, но и в споре» [9, с. 23]. Адресаты писателя схожи: это мелкая и средняя интеллигенция - учителя, судейские работники, военные, чиновники, врачи, инженеры, студенты, лица духовного звания. «Лица» внутренних читателей особенно интересны в контексте собственно дневниковой составляющей издания, то есть автокоммуникации (термин введен Ю. М. Лотманом, предполагает взаимоотношения в структуре «Я-Я» $[1$, с. 229], в которой выделяются «Я»-автора и «Я»-читателя).

Стоит отметить, что в своей публицистике Достоевский не раз обращался к теме ребенка и его страданий. В целом детская тема у Достоевского стоит особняком в его творчестве. Прежде всего это связано с его собственными детьми и переживаниями за них. Известно, с какой любовью Достоевский относился к своим детям и как тяжело переживал потерю своего первого ребенка. Воспоминания о детстве имели для Достоевского огромное значение. Он пронес через всю жизнь дорогие и радостные воспоминания о ранних своих годах и о родительском доме. Позже он писал: 
«Я очень часто задумываюсь и спрашиваю себя теперь: какие впечатления, большею частию, выносит из своего детства уже теперешняя современная нам молодежь?» $[10$, с. 151$]$.

Теме детства посвящены многие страницы «Дневника писателя». Особенно болезненно воспринимал писатель факты, связанные с детьми, которые выносились на публичное обсуждение в залы нового российского суда присяжных заседателей. Дело Кронеберга вызвало широкий отклик в средствах массовой коммуникации. Достоевский также включился в общий диалог-размышление о судьбе ребенка. К страницам «Дневника писателя», посвященным делу Кроненберга, обращались многие современные исследователи [7; 11; 12].

Кроненберга судили за то, что тот жестоко высек свою семилетнюю дочь шпицрутенами. Подсудимого оправдали благодаря видному адвокату Спасовичу, который в своей речи назвал поступок отца всего лишь «наказанием» за детские пороки, предел которому не установлен, а значит, не существует. Достоевский выступил против аргументов Спасовича: в февральском номере «Дневника писателя» 1876 года он, возмущенный решением суда, поместил подробный комментарий относительно защитной речи адвоката Спасовича. Писатель считал, что адекватного объяснения истязаниям быть не может: «... нельзя, говорю я, это создание, имеющее ангельский лик, несравненно чистейшее и безгрешнейшее, чем мы с вами, г-н Спасович <...> нельзя, говорю я, драть ее девятью рябиновыми “шпицрутенами", и драть четверть часа, не слушая ее криков: “папа, папа!”...» [8, т. 22, с. 67].

Достоевский показал, как в начале речи адвокат сознательно ослабляет свою коммуникативную позицию, желая вызвать доверие у слушателя: «Предполагаемый хитрец сам ищет защиты, да еще у вас же, у тех, которых собирался надувать! Таким приемом г-н Спасович сразу разбивает лед недоверчивости и хоть одной капелькой, а уже профильтровывается в ваше сердце» [Там же. С. 58]. Затем, показывая себя сторонником прогресса, адвокат использует тактику самопрезентации. Наконец, адвокат осуществляет психологическую девальвацию личности жертвы («если вы примете в соображение натуру дитяти»), а также использует лесть по отношению к слушателям («вы оправдаете, потому что глубокое понимание дела непременно ведет к тому, что тогда многое объяснится и покажется естественным»). Кроме того, Достоевский иронизирует над попыткой защитника Спасовича говорить на языке народа: «Вместо дитяти семи лет, вместо ангела, - перед нами явится девочка «шустрая», девочка хитрая, крикса, с дурным характером, которая кричит, когда ее только поставят в угол, которая «горазда кричать» (какие русизмы!»), лгунья, воровка, неопрятная и с скверным затаенным пороком» [Там же. С. 60].

Статьи, посвященные делу Кронеберга, явились настоящим гуманистическим манифестом, призывающим к уважению личности ребенка. «Слушайте, - обращается Достоевский к своему читателю, - мы не должны превозноситься над детьми, мы их хуже. И если мы учим их чему-нибудь, чтоб сделать их лучшими, то и они нас учат многому и тоже делают нас лучшими уже одним только нашим соприкосновением с ними. Они очеловечивают нашу душу одним только своим появлением между нами. А потому мы их должны уважать и подходить к ним с уважением к их лику ангельскому (хотя бы и имели их научить чему), к их невинности, даже и при порочной какой-нибудь в них привычке, - к их безответственности и к трогательной их беззащитности» [Там же. С. 68-69]. 
Ф. М. Достоевский сыграл важную роль и в деле Е. К. Корниловой: беременная женщина выбросила в окошко свою падчерицу и тут же призналась в содеянном. Достоевский написал о деле Корниловой большую статью в октябре 1876 г. в «Дневнике писателя» под названием «Простое, но мудреное дело». Простое, с одной стороны, дело показалось Достоевскому неоднозначным. Своим читателям Достоевский объяснил, что Корниловой, которая оказалась довольно добрым человеком, руководил «аффект беременности», при котором женщина помимо своей воли может совершать поступки, противоречащие ее настоящим, сознательным желаниям. А сослать ее в Сибирь - значит лишить уже двух живых существ (во время следствия Корнилова родила дочь) права на нормальную жизнь в полной семье.

Только благодаря статьям Достоевского в «Дневнике писателя» прежний приговор по делу Корниловой был кассирован, и 22 апреля 1877 г., когда вторично решалось её дело с новым составом суда и присяжных заседателей, Корнилова была оправдана. Достоевский посвятил этому статью «Освобождение подсудимой Корниловой» в апрельском «Дневнике писателя» за 1877 г. и главу первую «Заключительное разъяснение одного прежнего факта» в декабрьском «Дневнике писателя» за 1877 г.

Мы обратимся к статье «Дело родителей Джунсковских с родными детьми» (1877). Достоевский, с его вниманием к становлению российского суда, не мог не отреагировать на это дело. История Джунковских производит жуткое впечатление: эти родители секли своих детей, заставляли спать в грязной комнате с одним рваным одеялом, закрывали в холодном туалете, морили голодом. Но Джунковских в процессе судебного разбирательства оправдали: им удалось доказать, что дети заслужили наказание, потому что воровали и совершали другие дурные проступки.

Достоевский сам определяет своего адресата - это Джунковские, с одной стороны, а с другой - его читатель. Публицист сочиняет «фантастическую речь председателя суда» и адресует виновным свой приговор, но не уголовного суда, а суда совести и человечности.

Свой комментарий по поводу дела Джунковских Достоевский начинает с тактики противопоставления, которая станет основой его статьи. Писатель противопоставляет «написанный закон» и человеческий закон: «0, конечно, есть такой суд, который может их обвинить и ясно указать зачто, но не уголовный же суд с присяжными заседателями, судящий по написанному закону. А в написанных законах нигде нет статьи, ставящей преступлением ленивое, неумелое и бессердечное отношение отцов к детям» [8, т. 25, С. 183].

Нельзя отрицать несогласие публициста с решением суда, поэтому это несогласие и становится ведущим в этих диалоговых отношениях. Публицист не соглашается не только с решением суда, но и с равнодушным отношением к детям.

Используя тактику обобщения, Достоевский делится с читателем своими размышлениями о проблемах в законодательной сфере: «А в написанных законах нигде нет статьи, ставящей преступлением ленивое, неумелое и бессердечное отношение отцов кдетям. Иначе пришлось бы судить пол-России,-куды, гораздо больше» [Там же]. Об этом же можно прочитать в его статье, посвященной делу Кронеберга. Обобщенность Достоевский подчеркивает на морфологическом уровне, употребляя личные местоимения множественного числа: «У нас в судах случается» и глаголы 1 лица мн. ч. «вспомним», «заметим». Автор, используя интимный жанр беседы, сокращает дистанцию между собой и читателем, делится своим недовольством относительно судебной системы Российской Империи. Он приобщает читателей к этой проблеме, делая ее всеобщей. 
Но главное для писателя - пробуждение самосознания в отцах «случайного семейства», людях с «ленивыми», а не жестокими сердцами [Там же. С. 185]. Достоевский пытается встать на их место, сочувствует им. Использование риторических вопросов для суггестии не раз повторяются в речи публициста: «Тяжело ли им среди современного хаоса жизни, в котором так трудно что-нибудь понять? Или так мало ответила современная жизнь на их духовные стремления, на их желания, вопросы? Или, наконец, от непонимания кругом происходящего разложились и их понятия и уже больше не собрались и наступило разочарование?» [Там же. С. 184-185].

В своей статье Достоевский часто обращается к тактике уступки, которую условно можно назвать «да, но...». С ее помощью он доказывает свою позицию и становится убедительным для родителей и читателя: «То, что они секли розгами по лицу мертвую сестру за то, что она когда-то на них жаловалась, конечно, возмутительно и омерзительно. Но постараемся быть беспристрастнее и, клянусь вам, увидим, что даже и это лишь детская шалость, именно - это детская «фантастичность» [Там же. С. 186-187].

Достоевский ведет своего адресата (родителей и читателя) к диалогу согласия. Постепенно дистанция между автором и адресатом сокращается: сначала он пишет об отцах «случайного семейства» «они», - затем прямо обращается - «вы»: «Вы не холодные эгоисты. Ищите же любви и копите любовь в сердцах ваших» [Там же. С. 193]. Наконец, автор присоединяет себя к своему адресату, чтобы обратиться к высшей «инстанции» - Богу: «Если уж перестанем детей любить, то кого же после того мы сможем полюбить и что станется тогда с нами самими? Вспомните тоже, что лишь для детей и для их золотых головок Спаситель Наш обещал нам сократить времена и сроки [Там же]. Напоминание о Страшном суде должно обратить читателя к евангельской истине. Теперь Достоевский организует диалог с согласным читателем, надеясь на то, что тот имеет такие же морально-нравственные ориентиры, что и сам автор.

Мысли Достоевского относительно страдания ребенка отражены не только в его публицистике, но и в художественном творчестве. Так, в итоговом романе «Братья Карамазовы» (1880) этот мотив звучит в словах Ивана Карамазова. Герой Достоевского приводит примеры страданий детей из современной писателю действительности (в том числе, это дело Джунковских) и говорит: «Для чего познавать это чёртово добро и зло, когда это столько стоит? Да весь мир познания не стоит тогда этих слёзок ребёночка к „боженьке“... Пока ещё время, спешу оградить себя, а потому от высшей гармонии совершенно отказываюсь. Не стоит она слезинки хотя бы одного только того замученного ребёнка, который бил себя кулачонком в грудь и молился в зловонной конуре неискуплёнными слезами своими к „боженьке“!» $[8$, т. 14, c. 220$]$.

Иван Карамазов - это герой радикальный, атеист. В контексте внутреннего бунта (диалога с Алешей) Иван готов отказаться от высшей гармонии и всемирного счастья, если они достигаются детскими слезами и унижением. В своем атеизме Иван не близок автору - носителю веры. Так, почему же Достоевский вкладывает в уста Ивана мысли о страдании ребенка?

В действительности, мнения Алеши и Ивана - это «квинтэссенция взглядов» самого писателя. Итогом разговора становится отрицательный ответ Алеши на возможность существования гармонии и истины, достигнутых при помощи детоубийства, что полностью совпадает с мыслями самого Ивана. В этот момент предельно заостряется постановка вопроса о гуманизме: одна слезинка ребёнка противопоставляется достигнутой такой ценой мировой гармонии. 
Таким образом, в «Дневнике писателя» Ф. М.Достоевский предположил, что должен был бы сказать этим родителям председатель суда, который дал им возможность остаться безнаказанными. От лица этого председателя Достоевский говорил, что Джунковским еще предстоит суд их собственной совести, и в первую очередь им стоит задуматься над вопросом о том, почему дети вообще совершали проступки. По мысли Достоевского, причины эти, конечно, заключаются в поведении родителей. «Не разъясню, а прикажу, не внушу, а заставлю», - такой подход к воспитанию ребенка только развращает, ранит безгрешную и чистую еще душу так сильно, что она либо закрывается, либо учится хитрить. Достоевский напоминал родителям о том, что любовь - это труд и долг, а сам горячо верил в силу любви и бессилие насилия морального и физического.

\section{Ссылки / References}

1. Каган М. С. О педагогическом аспекте теории диалога // Диалог в образовании: сб. материалов конференции. Серия «Symposium», выпуск 22. СПб.: Санкт-Петербургское философское общество, 2002. С. 150-152.

2. Новая философская энциклопедия. Т. І. М.: Мысль, 2000. 721 с.

3. Сайко Э. В. О природе и пространстве «действия» диалога // Социокультурное пространство диалога. М.: Наука, 1999. С. 9-32.

4. Бахтин М. М. Проблемы поэтики Достоевского. М.: Советский писатель, 1963. 363 с.

5. Бонецкая Н. К. М. М. Бахтин и традиции русской философии // Вопросы философии. 1993. № 1. C. 83-93.

6. Шалимова Е. В. Специфика диалога в публицистическом тексте: трехмерная картина взаимоотношений // Baikal Research Journal. Иркутск: БГУ, 2013. URL: https:// cyberleninka.ru/article/n/spetsifika-dialoga-v-publitsisticheskom-tekste-trehmernayakartina-vzaimootnosheniy (дата обращения: 10.04.2021).

7. Гаврилова Л. А. Двунаправленность авторского замысла в «Дневнике писателя» Ф. М. Достоевского // Верхневолжский филологический вестник. Ярославль: ЯГПУ им. К. Д. Ушинского, 2015. № 2. С. 145-150.

8. Достоевский Ф. М. Полное собрание сочинений в тридцати томах / АН СССР, Институт русской литературы (Пушкинский дом); редкол.: В. Г. Базанов (гл. ред.), Г. М. Фридлендер (зам. гл. ред.), В. В. Виноградов и др. Л.: Наука. Ленинградское отделение, 1972-1990.

9. Ермошин Ф. А. Автор и читатель в публицистике Достоевского 70-х гг. XIX в.: дис. ... канд. филол. наук. М., 2009. 263 с.

10. Безрукова Т. В. Социология детства в романах Ф. М. Достоевского // Инженерные технологии и системы. Саранск, 2007. С. 151-155.

11. Немкевич И. В. Дело Кронеберга: «ступенька лестницы» к правам ребенка // Известия Гомельского государственного университета имени Ф. Скорины. Гомель, 2016. № 2 (95). С. 94-97.

12. Фёдорова Е. А. Сопоставительный анализ аргументации Ф. М. Достоевского и В. Д. Спасовича (по делу С. Л. Кроненберга 1876 г.) // Сопоставительные исследования 2018. Вып. 15. Воронеж: РИТМ, 2018. С. 218-221. 